\title{
Detection of aberrant methylation of a six-gene panel in serum DNA for diagnosis of breast cancer
}

\author{
Ming Shan ${ }^{1,2, *}$, Huizi Yin ${ }^{1, *}$, Junnan $\mathrm{Li}^{3}$, Xiaobo $\mathrm{Li}^{4}$, Dong Wang ${ }^{5}$, Yonghui Su ${ }^{1}$, \\ Ming Niu ${ }^{1}$, Zhenbin Zhong ${ }^{1}$, Ji Wang ${ }^{1}$, Xianyu Zhang ${ }^{1}$, Wenli Kang ${ }^{6}$, Da Pang ${ }^{1,2}$ \\ ${ }^{1}$ Department of Breast Cancer Surgery, The Affiliated Tumor Hospital of Harbin Medical University, Harbin, P.R. China \\ ${ }^{2}$ Translational Medicine Research and Cooperation Center of Northern China, Heilongjiang Academy of Medical Sciences, \\ Harbin, P.R. China \\ ${ }^{3}$ Department of Epidemiology and Biostatistics, Harbin Medical University, Harbin, P.R. China \\ ${ }^{4}$ Department of Pathology, Harbin Medical University, Harbin, P.R. China \\ ${ }^{5}$ College of Bioinformatics Science and Technology, Harbin Medical University, Harbin, P.R. China \\ ${ }^{6}$ Department of Oncology, General Hospital of Heilongjiang Province Land Reclamation Headquarters, Harbin, P.R. China \\ *These authors have contributed equally to this work
}

Correspondence to: Da Pang, e-mail: pangda@ems.hrbmu.edu.cn

Keywords: breast cancer, DNA methylation, diagnosis, MethyLight

Received: December 08, $2015 \quad$ Accepted: February 11, 2016

Published: February 23, 2016

\section{ABSTRACT}

Detection of breast cancer at an early stage is the key for successful treatment and improvement of outcome. However the limitations of mammography are well recognized, especially for those women with premenopausal breast cancer. Novel approaches to breast cancer screening are necessary, especially in the developing world where mammography is not feasible. In this study, we examined the promoter methylation of six genes (SFN, P16, hMLH1, HOXD13, PCDHGB7 and RASSF1a) in circulating free DNA (cfDNA) extracted from serum. We used a high-throughput DNA methylation assay (MethyLight) to examine serum from 749 cases including breast cancer patients, patients with benign breast diseases and healthy women. The sixgene methylation panel test achieved $79.6 \%$ and $82.4 \%$ sensitivity with a specificity of $72.4 \%$ and $78.1 \%$ in diagnosis of breast cancer when compared with healthy and benign disease controls, respectively. Moreover, the methylation panel positive group showed significant differences in the following independent variables: (a) involvement of family history of tumors; (b) a low proliferative index, ki-67; (c) high ratios in luminal subtypes. Additionally the panel also complemented some breast cancer cases which were neglected by mammography or ultrasound. These data suggest that epigenetic markers in serum have potential for diagnosis of breast cancer.

\section{INTRODUCTION}

Breast cancer is a complex and heterogeneous disease and one of the leading causes of death among women. Detection of breast cancer at an early stage is the key for successful treatment and improvement of outcome. Although a significant decline in breast cancer mortality between 1992 and 1996 is believed to be due, in part, to early diagnosis by screening mammography, however the limitations of mammography [1] are well recognized, especially for those women with premenopausal breast cancer. In developing countries, the extensive laboratory and clinical infrastructure required for mammographic screening, as well as the high cost of mammography precludes such an approach. Further, given that the majority of women in many developing countries are under the age of 40 years, the problem of detecting premenopausal breast cancer is of particular important in such settings. Despite the availability of mammography and the prevalence of self-examination, additional benefits can still be gained from additional screening methodologies [2]. Therefore, developing novel approaches for the early diagnosis of breast cancer has important clinical implications. 
Epigenetic change, including DNA methylation, is one of the most common molecular alterations in human neoplasia, including breast cancer [3]. CpG islands located in promoter regions of tumor suppressive genes are generally unmethylated in normal cells. However, in cancer cells, aberrant hypermethylation of these promoter regions is associated with transcriptional silencing. Hypermethylation is therefore an alternative mechanism for the inactivation of tumor suppressor genes $[4,5]$. Since gene hypermethylation has been found to be a common and early event in many tumor types, including breast tumors $[6,7]$, it has emerged as a promising target for detection strategies involving clinical specimens $[8,9]$. Serum or plasma is a more readily accessible bodily fluid, and provision of a specimen does not require the presence of a specialist. DNA is known to be released into serum/plasma, which is enriched for tumor DNA in cancer patients [10]. Several recent studies have shown that it is possible to detect tumor-specific methylation alterations in serum DNA from head and neck, lung, and colon cancer patients. Importantly, tumor cell-specific DNA methylation in serum is not limited to patients with metastatic cancer but is also present in serum from patients with early organconfined tumors [11-14]. Neoplastic DNA in serum most likely arises from cells that have left the site of the primary lesion and have invaded the circulatory system but lack the capacity of metastasis to new organs, or it may be released from the primary tumor as free DNA from nonviable (apoptotic) neoplastic cells [8,9].

However, in spite of the promise of such biomarkers, there are several barriers that impede fast progress toward their clinical application. Major limitations to further development for clinical application might be that these studies investigated only small numbers of methylated targets, or fewer breast cancer and matched control specimens, and validation with larger patient cohorts was not pursued [9, 15]. Furthermore, many studies have focused on investigating the methylation patterns in serum from healthy women and those with breast cancer, but only rare studies using benign breast diseases as control to identify the potential clinical applications of serum DNA methylation. Other limitations include the utilization of different technologies by different laboratories with a range of detection sensitivity, varying emphasis on quantitation, and the utilization of different sample processing methodologies and different reference materials as controls for the analysis of hypermethylation degree by the same technology [16]. In our paper unpublished, we had chosen lots of genes hypermethylated in breast cancer tissue and hypomethylated in the match normal breast tissue from the TCGA database. However many of them didn't show hypermethylation in our breast cancer patients. The genes we selected, SFN, P16, hMLH1, PCDHGB7 and RASSF1a had the most frequency of methylation in breast cancer samples in our previous research and the methylation of some of the genes happened at the early stage of breast cancer. Additionally, they have previously been shown to undergo cancer-specific methylation according to reports of clinical or fundamental studies [17-22]. So in this study, the promoter methylation of the six-gene panel was examined by using serum collected from more than 749 cases, including breast cancer patients, patients with benign breast diseases and healthy women to prove if they are suitable for diagnostic biomarkers of breast cancer in serum. Moreover we added a new methylated site of HOXD13 in the promoter region, which didn't exist in our previous research, but showed significant methylation in serum from breast cancer patients comparing to benign breast diseases patients and healthy women in this study $(\mathrm{P}<0.05)$. We also compared our gene panel diagnosis alongside with mammography and ultrasound, which were routine diagnostic tools for breast cancer in clinic. Our study suggests that epigenetic markers in serum provide reliable targets for breast cancer diagnosis and optimized epigenetic biomarkers would have great potential in clinical application.

\section{RESULTS}

In this study, we assessed the promoter methylation of an six-gene panel (SFN, P16, hMLH1, HOXD13, PCDHGB7 and RASSF1a) in serum samples by using MethyLight, to investigate whether it could be used for diagnosis of breast cancer or not. All of these genes are representatives of a variety of cellular pathways that are involved in cancer, including DNA binding, cell cycle/checkpoint control, developmental regulation, chromatin binding and cytokine activity (Supplementary Table S1). An overview of the methylation frequency in the studied serum samples of all the three groups is given in Table 1. HOXD13 is rarely methylated in the sera from breast cancer patient group (13.81\%). However, the unmethylation frequency of HOXD13 is significantly increased in the sera from healthy women $(97.55 \%)$ and patient group with benign breast diseases (99.58\%). Conversely PCDHGB7 and SFN exhibited better sensitivities in breast cancer (55.60\% and $73.51 \%$ ), but the specificity was unsatisfied. Most of the candidate markers were significantly methylated in sera from breast cancers than non-breast tumors $(\mathrm{P}<0.05$, Figure 1$)$.

According to the previous researches [23], multiple marker combinations were able to improve the sensitivity and specificity of methylation biomarkers for tumor diagnosis. So next we performed ROC curve analysis for all the samples to determine the sensitivity and specificity of the six-gene ensemble.

The R RandomForest analysis randomly divided all the cases into two data set, including the training set (128 breast cancer cases vs 114 benign breast disease cases and vs 112 healthy women cases) and the test set (125 cancer vs 104 benign disease and vs 104 health). The optimal 
Table 1: Sensitivity and specificity of serum-based detection of aberrantly methylated genes in all groups

\begin{tabular}{|c|c|c|c|c|c|c|}
\hline \multirow[t]{2}{*}{ Genes } & \multicolumn{2}{|c|}{$\begin{array}{c}\text { Sensitivity in } \\
\text { Breast Cancer }\end{array}$} & \multicolumn{2}{|c|}{$\begin{array}{c}\text { Specificity } \\
\text { in Benign Breast Diseases }\end{array}$} & \multicolumn{2}{|c|}{$\begin{array}{c}\text { Specificity } \\
\text { in Healthy Controls }\end{array}$} \\
\hline & $\begin{array}{l}\text { Methylation } \\
\text { Positive }\end{array}$ & $\%$ & $\begin{array}{l}\text { Methylation } \\
\text { Negative }\end{array}$ & $\%$ & $\begin{array}{l}\text { Methylation } \\
\text { Negative }\end{array}$ & $\%$ \\
\hline hMLH1 & 75 of 268 & 27.99 & 184 of 236 & 77.97 & 210 of 245 & 85.71 \\
\hline RASSF1a & 46 of 268 & 17.16 & 217 of 236 & 91.95 & 220 of 245 & 89.67 \\
\hline P16 & 60 of 268 & 22.39 & 199 of 236 & 84.32 & 204 of 245 & 83.27 \\
\hline PCDHGB 7 & 149 of 268 & 55.60 & 129 of 236 & 54.66 & 129 of 245 & 52.65 \\
\hline$S F N$ & 197 of 268 & 73.51 & 92 of 236 & 38.98 & 102 of 245 & 41.63 \\
\hline HOXD13 & 37 of 268 & 13.81 & 235 of 236 & 99.58 & 239 of 245 & 97.55 \\
\hline
\end{tabular}

\section{Methyl Ratios}

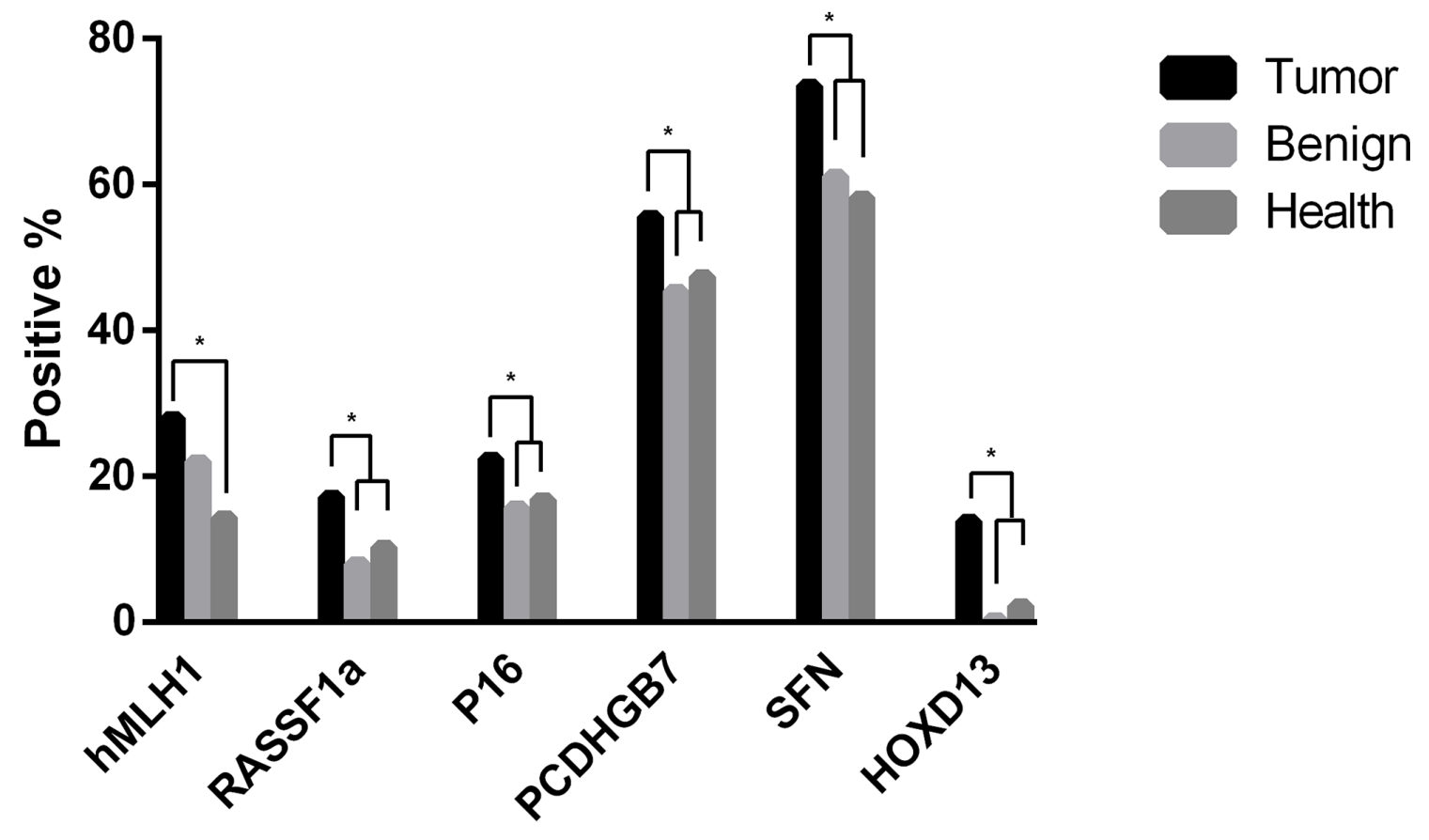

Methylated Genes

Figure 1: Methylation frequency of all candidate markers in serum from breast cancer versus non-breast tumors. $* P<0.05$.

threshold value for the six-target union to distinguish cancer from controls (benign diseases and health) was determined firstly in the training data set. Then the analysis model was validated in the test data set to calculate the AUC value, the sensitivity and specificity. There were no significant differences between the training and test data set with respect to any of the measured demographic or clinicopathologic characteristics or with respect to tumor stage among the cases. According to this analysis, the sixmarker panel could discriminate between breast cancer patients and healthy women with a sensitivity of $79.6 \%$ and a specificity of $72.4 \%$ (AUC, 0.727 (95\% CI, 0.712 to 0.742), $\mathrm{P}<0.001$, Figure 2A). Additionally, the six-marker panel is able to distinguish breast cancer patients from women with benign breast diseases with higher specificity and sensitivity (78.1\% and 82.4\%; AUC, 0.789 (95\% CI, 0.775 to 0.797$), \mathrm{P}<0.001$, Figure $2 \mathrm{~B}$ ). It is worth noting that there was no significant differences between benign breast diseases and healthy women when using this panel (AUC, 0.486 (95\% CI, 0.471 to 0.492), $\mathrm{P}>0.05$, Figure 2C). Different AUC values of these six gene markers were also tested and the six-gene panel remains the top. 
The methylation status of the six-gene panel in the breast cancer patients of the test set was further analyzed for association with known clinicopathologic characteristics of breast cancer, including age at diagnosis, family history of tumors, tumor grade, tumor size, node status, and hormonereceptor status, etc (Table 2). The family history of tumors means the first degree relatives of patients have or died of malignant tumors, including lung cancer, hepatocarcinoma, breast cancer and so on. There are more patients with low ki-67 index in the methylation panel positive group. And the percentage of ki-67 positive staining is lower than $30 \%$ in most of them. So statistical analysis revealed significant differences in the following independent variables: $(a)$ involvement of family history of tumors $(\mathrm{P}=0.0249)$; (b) a low proliferative index, ki-67 $(\mathrm{P}=0.0356)$; (c) high methylated frequency in luminal subtypes $(\mathrm{P}=0.0319)$. In the methylation panel positive group, it occupied $59.22 \%$ in luminal-A subtype and $25.24 \%$ in luminal-B subtype. However in the methylation panel negative group, it became lower and showed $36.36 \%$ in luminal-A type and $22.73 \%$ in luminal-B type. The rest of the variables analyzed displayed no statistically significant differences. Next we investigated the consistency among the six-gene methylation panel, mammography, and ultrasound for breast cancer diagnosis by Kappa conformance test. Comparing mammography with ultrasound, significant consistency was observed $(\mathrm{P}=0.0012)$, and the consistency rate was high $(0.856$, shown in Table 3). In further calculation of the consistency between six-gene panel and either mammography or ultrasound, there was also significant statistical consistency. Moreover, in the mammography diagnosis group, there were 10 breast cancer cases that were panel methylation positive but with mammography diagnosis results negative for breast cancer. In the ultrasound group, 5 breast cancer cases were neglected. However, the panel methylation test method could show that these people had breast cancer (Figure 3). In addition, we further divided tumor sizes into two groups, decreased from $>2 \mathrm{~cm}$ to $\leq 1 \mathrm{~cm}$, the sensitivity of mammography declined from $88.24 \%$ to $81.82 \%$ (Table 4). On the other hand, the diagnostic sensitivity of methylated gene panel increased modestly along with tumor size decrease.

\section{DISCUSSION}

To investigate new methods for early breast cancer diagnosis, we tested an six-gene panel by using a bloodbased PCR assay for methylated circulating free DNA (cfDNA) in two independent serum sets with a total of 749 serum samples, including sera collected from breast cancer patients, women with benign breast diseases and healthy women. Among these six genes, four of them (SFN, hMLH1, HOXD13 and PCDHGB7) have not been investigated previously as blood-based biomarkers for breast cancer diagnosis. However, the high methylation frequency of these genes in breast tumor tissues, including DCIS, found in our previous research implied their potential application for early breast cancer detection. Circulating serum DNA, presumably shed from the original primary tumor, can be retrieved and tested for genetic and epigenetic alterations. Previous studies have reported various genetic and epigenetic alterations in matched samples from tumor tissue and serum in patients with cancer [24-26]. Although knowledge of the underlying mechanism of this circulating DNA is still limited [27], some evidences suggested that the cfDNA is released from the tumor as a glyconucleoprotein complex that may protect it from degradation by nucleases [28]. It remains unclear whether release of tumor DNA into serum is associated with tumor necrosis, apoptotic cell death, or other selective cellular processes.

Interestingly, in this study, aberrant methylation was detected not only in patients with breast cancer but also in a small proportion of control subjects. Methylation of several genes has been reported previously in nonmalignant tissues and serum DNA of smokers. The presence of aberrant methylation in serum DNA could be a marker of disease
A

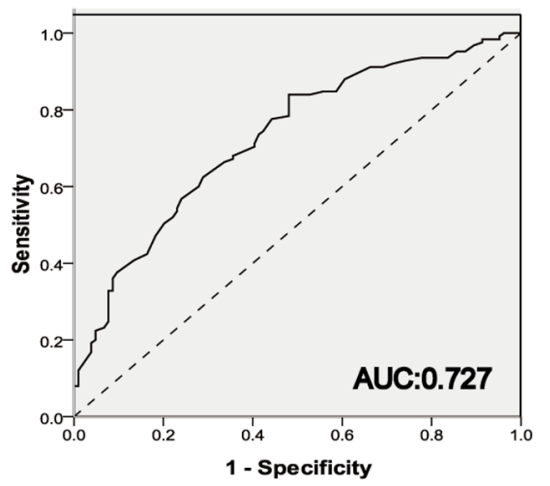

B

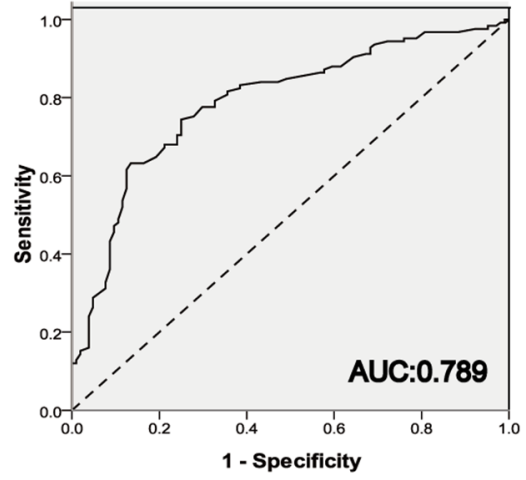

C

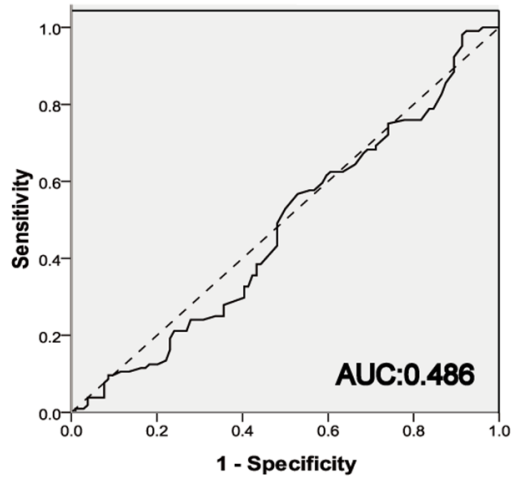

Figure 2: ROC curve analysis of the six-gene panel among all the groups. A. Between Breast Cancer and Health; B. Between Breast Cancer and Benign Breast Diseases. C. Between Benign Breast Diseases and Health. 
Table 2: Pathological characteristics of breast carcinomas showing a statistically significant difference between the six-marker panel positive and negative groups

\begin{tabular}{|c|c|c|c|c|c|}
\hline Factors & $\begin{array}{c}\text { Panel } \\
\text { Positive }\end{array}$ & $\%$ & $\begin{array}{c}\text { Panel } \\
\text { Negative }\end{array}$ & $\%$ & $P$ Value \\
\hline \multicolumn{6}{|l|}{ Patient characteristics } \\
\hline Age at diagnosis & $50.86 \pm 11.30$ & & $49.44 \pm 8.66$ & & 0.3549 \\
\hline BMI at diagnosis $\left(\mathrm{kg} / \mathrm{m}^{\wedge} 2\right)$ & $24.06 \pm 3.97$ & & $23.10 \pm 3.08$ & & 0.0788 \\
\hline Frequencies & & & & & 0.0249 \\
\hline Family History of Tumor & 29 & 28.16 & 1 & 4.55 & \\
\hline no Family History of Tumor & 74 & 71.84 & 21 & 95.45 & \\
\hline \multicolumn{6}{|l|}{ Tumor characteristics } \\
\hline Size & & & & & 0.6313 \\
\hline$\leq 2.0$ & 39 & 37.86 & 10 & 45.45 & \\
\hline$>2.0$ & 64 & 62.14 & 12 & 54.55 & \\
\hline Grade & & & & & 0.9533 \\
\hline Well differentiated & 5 & 4.86 & 1 & 4.55 & \\
\hline Moderately differentiated & 82 & 79.61 & 17 & 77.27 & \\
\hline Poorly differentiated & 16 & 15.53 & 4 & 18.18 & \\
\hline Lymphatic-metastasis & & & & & 0.562 \\
\hline No & 48 & 46.6 & 13 & 59.09 & \\
\hline$\leq 3$ & 26 & 25.24 & 4 & 18.18 & \\
\hline$>3$ & 29 & 28.16 & 5 & 22.73 & \\
\hline$K i-67$ & & & & & 0.0356 \\
\hline$\leq 30 \%$ & 93 & 90.29 & 16 & 72.73 & \\
\hline$>30 \%$ & 10 & 9.71 & 6 & 27.27 & \\
\hline P53 & & & & & 0.4211 \\
\hline Positive & 24 & 23.3 & 7 & 31.81 & \\
\hline Negative & 79 & 76.7 & 15 & 68.19 & \\
\hline Subtypes & & & & & 0.0319 \\
\hline Luminal-A & 61 & 59.22 & 8 & 36.36 & \\
\hline Luminal-B & 26 & 25.24 & 5 & 22.73 & \\
\hline Her-2 & 10 & 9.71 & 4 & 18.18 & \\
\hline Triple-negative & 6 & 5.83 & 5 & 22.73 & \\
\hline
\end{tabular}

(an early neoplastic effect), exposure (a biologic effect of an environmental factor) or both. The presence of aberrant methylation in healthy subjects may reflect chronic exposure to still unidentified environmental carcinogenic factors or inherited oncogenic mutations, because we found more breast cancer patients who had family history of tumors in the methylation positive panel group $(28.13 \%$, see in Table 2). Longitudinal epidemiologic studies confirming the association between the risk of developing precancerous lesions and the aberrant gene methylation and also demonstrated that the basis of methylation was related to environmental factors and oncogenetic (such as BRCA1/ BRCA2) mutations. Thus, detection of methylation may help to identify high-risk individuals so that the breast cancer could be early diagnosed by using more intensive standard evaluation methods. Moreover, cfDNA could originate from other normal organs in the body and it is also released during cell aging, apoptosis or other procedure. 
Table 3: Consistency tests among panel, mammography and ultrasound groups

\begin{tabular}{lcc}
\hline Group & Consistency Rate & $P$ value \\
\hline Mammography and Ultrasound & 0.856 & 0.0012 \\
Panel and Mammography & 0.8 & $\mathbf{0 . 0 0 6}$ \\
Panel and Ultrasound & 0.832 & $\mathbf{0 . 0 0 0 8}$ \\
\hline
\end{tabular}

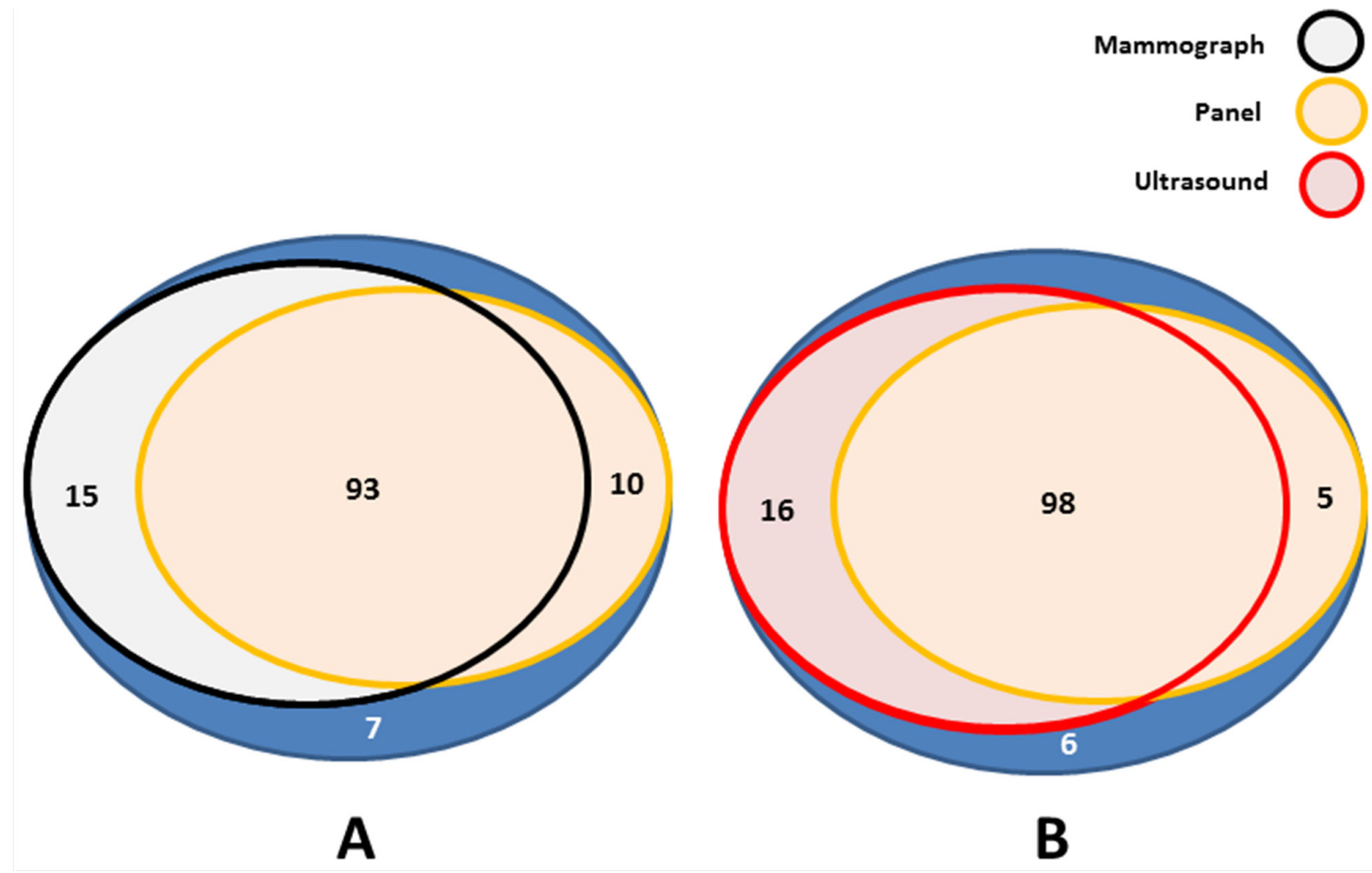

Figure 3: Positive diagnosis of breast cancer by mammography, ultrasound and six-gene panel in breast cancer group. A. The diagnosis consistency of breast cancer between panel methylation and mammography. B. The diagnosis consistency of breast cancer between panel methylation and ultrasound.

Table 4: Diagnostic sensitivities for mammography and six-gene methylation panel in different tumor sizes

\begin{tabular}{lcc}
\hline Diagnosis Method & Tumor Size & Sensitivity (\%) \\
\hline Mammography & & $60 / 68(88.24)$ \\
& $>2 \mathrm{~cm}$ & $9 / 11(81.82)$ \\
Six-gene Methylation Panel & $\leq 1 \mathrm{~cm}$ & $54 / 67(80.60)$ \\
& $>2 \mathrm{~cm}$ & $12 / 14(85.71)$ \\
\hline
\end{tabular}

As previous researches reported [18, 29], different organs showed tissue-specific methylation patterns. In this study, we identified low frequency of genes methylation in the serum from control groups, which may release from other tissues than the breast tissue. But it is obviously that the frequency of the gene methylation from the breast cancer patients was significantly higher than that in control groups. At last, these data provide strong, albeit indirect, evidence that the DNA containing the methylation of the specified gene originates from the primary breast cancer and is not affected by the serum DNA from nonmalignant tissues. Accumulating data on these methylation markers including the six genes tested in this study (HOXD13, SFN, RASSF1a, P16, PCDHGB7, and hMLH1) is of interest for further evaluation as serum- or serum-based biomarkers for the detection and monitoring of breast cancer patients. 
Detection of methylation in circulating DNA depends on the ability of the assay to detect methylated DNA in a background of wild-type DNA (estimated at $>1: 1000$ ). In our experience and that reported by others [30, 31], MethyLight is more sensitive than conventional MSP. Methylation changes in carcinogenesis are often heterogeneous, and no single gene has been found methylated in every breast cancer specimen so far. Furthermore, in most studies investigating methylation levels by using single gene, the sensitivity has been generally low [17]. Therefore, it is considered that a panel of genes for breast cancer screening procedures would improve the sensitivity. In our current study, we were able to define a biomarker panel with the significant values for breast cancer diagnosis by investigation of a strong and realistic cohort of control samples (including patients with benign breast diseases and healthy women). Our six-gene panel indicated significantly high sensitivity of $82.4 \%$ and also high specificity of $78.1 \%$ with an AUC of 0.789 . Meanwhile according to the negative result of the ROC analysis between benign breast diseases and healthy women, this panel showed better clinical application for breast cancer diagnosis.

Regarding mammography, with a sensitivity of $>70 \%$ and a specificity of $>85 \%$, a reliable biomarker panel for early detection of breast cancer in cfDNA need to reach comparable values. In our study, the mammography used for breast cancer diagnosis achieved the sensitivity of $86.4 \%$. The sensitivity of ultrasound was a little higher than mammography, since ultrasound for breast cancer diagnosis may be suitable for dense breast tissue and small sized breast tumors [32, 33]. However, the accuracy of ultrasound diagnosis depends on the experience of radiologists, so it is not objective and will be limited in the clinical application in future. Sensitivity of mammography declines drastically in patients with dense breast tissue or small sized tumors [34]. Meanwhile, mammographic density is a high risk factor for breast cancer, especially for small sized breast cancer $[35,36]$. In our current research, we found that the sensitivity of mammography is associated with tumor size. When tumor size is more than $2 \mathrm{~cm}$, the sensitivity of mammography achieved to $88.24 \%$, however, when it less than $1 \mathrm{~cm}$, the sensitivity declined to $81.82 \%$. It implies that in some breast cancer cases with small sized tumors, the mammography or ultrasound test might neglect them. But the diagnostic sensitivity of methylated gene panel increased modestly along with tumor size decrease. So we hypothesize that breast cancer patients with small sized or early breast tumors $(<1 \mathrm{~cm})$ may benefit from the methylated gene panel examination. Prospectively, methylation panel analysis may be a complement with mammography screening, as the sensitivity of which is low in patients with small sized or early breast tumors.
In the analysis of clinical characteristics correlated with the panel methylation positive group, panel methylation positive samples were more frequent in the lower proliferation group $(90.29 \%)$ and luminal subtypes $(84.46 \%)$. This association between methylated modification profiles and luminal type breast cancer was similarly referred to many previous investigations [37-39], which suggests that different molecular subtypes of breast cancer would be caused by distinct genetic and epigenetic mechanisms [40]. Moreover, the low proliferation index might also reflected early status of breast cancer.

In summary, the six-marker panel with HOXD13, SFN, RASSF1a, P16, PCDHGB7, and hMLH1 exhibits significantly aberrant methylation in serum cfDNA from breast cancer patients compared with both age-matched healthy women and women with a benign breast disease. However the sensitivity and specificity were not very satisfied to distinguish breast cancers from controls. So our next goal is to develop more useful biomarkers for early breast cancer detection with a higher sensitivity and specificity comparable to the six-gene promoter methylation panel. In addition, other approaches, such as investigations of copy-number variations (CNVs), loss of heterozygosity ( $\mathrm{LOH})$, and point mutations in cfDNA, could be also combined to improve the sensitivity and specificity of the panel. Altogether, these approaches could allow for the establishment a biomarker panel offering sensitivity and specificity comparable to that of mammographic examination. Of importance, such a blood-borne screening test would be more convenient for the patient and less expensive for the health-care system.

\section{MATERIALS AND METHODS}

\section{Study population and clinical characteristics}

This study was approved by the Human Research Ethics Committee and Clinical Trials Committee of Harbin Medical University in accordance with the Helsinki Declaration. Written informed clinical research consents were obtained for all patients. All 504 serum samples, except for healthy serum samples, were acquired at the Affiliated Tumor Hospital of Harbin Medical University, Harbin, China from 2009 to 2012, including various sera from 236 benign breast disease patients, including fibroadenoma, desmoid tumors, benign phyllodes tumors, mastopathy, papilloma, duct ectasia and harmatoma. The 245 healthy serum samples were acquired from the Affiliated Tumor Prevention and Treatment Institution of Harbin Medical University, Harbin, China from 2009 to 2012. All 3 sample groups (cancer, benign diseases and healthy controls) were selected from women in the age range $40 \sim 60$ to rule out the effects of age on DNA methylation [29]. All the breast cancer patients in the study 
had simultaneously been examined by the mammography and ultrasound before surgery in the hospital. The breast imaging reporting and data system (BI-RADS) diagnosis of mammography and ultrasound followed the standard of the NCCN Breast Cancer Guideline (2015 version).

Immunohistochemistry (IHC) staining for ER, PR and Her-2 were performed as a routine examination in breast cancer clinics. To qualify as Her-2 positive for this study, a case had to demonstrate either a 3+ (strong positive) IHC score or a Her-2 fluorescence in situ hybridization amplification ratio of greater than 2.2. For p53 and ki-67 IHC, only nuclear labeling was scored. For p53, we regarded labeling of $>30 \%$ of nuclei to be aberrant overexpression (which correlates well but not perfectly with p53 mutation) [41]. The ki-67 cut-off point of 13\% was used to designate a tumor as high proliferation subtype [42].

According to the IHC characteristics, cases were categorized into one of 4 categories based upon accepted and previously validated IHC surrogate profiles. Luminal-A tumors were immunoreactive for ER and/or PR, negative for her-2 or low proliferation. ER+ and/or PR+, and either her-2+ and/or high proliferation were considered luminal-B tumors. The subtype of Her-2 defined as ER- and PR-, her$2+$. On the basis of published criteria, all the basal-like cases were approximated as triple negative phenotype (ER-/PR-/ her-2-). Therefore, we used TNBC instead.

\section{Collection and processing of samples and DNA preparation}

At the enrollment visit, approximately $5 \mathrm{~mL}$ of peripheral blood was drawn into a blood collection tube before physical examination or surgery, and all were transferred to the study laboratory within 2 hours of collection for processing. Circulating free DNA (cfDNA) was obtained from $1 \mathrm{~mL}$ of serum by using the QIAamp Circulating Nucleic Acid Kit (50) (Qiagen, Hilden, Germany) following the manufacturer's protocols.

\section{Bisulfite treatment and MethyLight}

Bisulfite conversion of DNA was performed using the EZ DNA Methylation kit (Zymo Research, Orange, CA, USA) following the manufacturer's protocols. A detailed list of the nucleotide sequences for MethyLight primers and probes in the promoter or 5' end region for all analyzed loci is provided in Supplementary Table S2. All probes for the target methylation sites are not detectable in white blood cells (WBC).

TaqMan MGB (Applied Biosystems, Foster City, CA, USA) PCR with primers specific for the bisulfiteconverted methylated sequence for a particular locus and with globin reference primers were performed separately. TaqMan MGB probes provided a significant improvement in assay specificity, and due to their smaller size, allowed for a more flexible assay design. All analyzed samples were within the different assays' range of sensitivity and reproducibility based on amplification of the internal reference standard (cycle threshold (CT) value for globin of 35 or less). The gene of interest was called methylated if the CT of at least two of three PCR replicates for each specimen had a value of less than 40 cycles [43-45]. Genes of interest were considered unmethylated if its $\mathrm{CT}$ was not measurable or was $\geq 40$. The ratio between the value of the gene of interest and globin obtained by TaqMan analysis was used as a measure to represent the relative level of methylation in that particular sample $\left(2^{-\Delta \mathrm{CT}}\right)[43]$. The $\Delta \mathrm{Ct}$ was calculated as (CT $\mathrm{Carget} \mathrm{gene}-\mathrm{CT}$ Reference). The amplification efficiency of the test genes and of the reference gene, globin, was examined using serial dilutions of DNA with a 100-fold range and gene-specific primers for each gene and globin. All amplification efficiencies were similar (data not shown).

Fluorogenic PCRs were carried out in a reaction volume of $20 \mu \mathrm{L}$ consisting of $600 \mathrm{nmol} / \mathrm{L}$ of each primer; $200 \mathrm{nmol} / \mathrm{L}$ probe; 0.75 units of platinum Taq polymerase (Invitrogen, Carlsbad, CA); $200 \mu \mathrm{mol} / \mathrm{L}$ each of dATP, dCTP, dGTP, and dTTP; $16.6 \mathrm{mmol} / \mathrm{L}$ ammonium sulfate; $67 \mathrm{mmol} / \mathrm{L}$ Trizma; $6.7 \mathrm{mmol} / \mathrm{L} \mathrm{MgCl} ; 10 \mathrm{mmol} / \mathrm{L}$ mercaptoethanol; and $0.1 \%$ DMSO. Two microliters of treated DNA solution was used in each MethyLight reaction. Amplifications were carried out in 96-well plates in a 7500 Sequence detector (Perkin-Elmer Applied Biosystems, Foster City, CA). Each plate consisted of samples and multiple water blanks, as well as positive and negative controls.

\section{Statistical methods}

The methylation frequency comparison was evaluated by Chi-square test. The diagnosis consistency was calculated by Kappa conformance test. Pathological characteristic data comparison used the Student t test, Chisquare test, Fisher exact test, and Mann-Whitney U test. All tests were performed by SPSS 17.0, GraphPad Prism 5.0 (GraphPad Software Inc., La Jolla, CA, USA) and ROC curve analysis was calculated by the RandomForest of R Programming Language (3.2.0). $P$ values of $<0.05$ were considered significant.

For the ROC curve analysis, we divided two main groups, Cancer vs Benign and Cancer vs Health and two sets for gene promoter methylation analysis were built randomly through the $\mathrm{R}$ RandomForest Package, which called the training data set and the test data set. The training data set included 128 breast cancer cases, 114 benign breast disease cases and 112 healthy women cases; the test data set had 125 breast cancer cases, 104 benign breast disease cases and 104 healthy cases. The rest of the samples were abandoned because globin was not detected or to eliminate any differences between the training and test data sets with respect to any of the measured demographic or clinicopathologic characteristics, such as age, tumor stage, tumor size, etc.

Optimum cutoff values with respect to prediction of case-control status were built in the training data set, 
and then validated in the test data set and the AUC value was yielded. The final AUC was the mean value through 100 duplicated tests above. The sensitivity of MethyLightbased detection of hypermethylation in serum was calculated as the number of positive tests among the cancer cases divided by the number of total cancer cases. The specificity was calculated as the number of negative tests among the controls divided by the total number of controls.

\section{ACKNOWLEDGMENTS}

We thank the doctors and the patients who participated in this study. This article is subject to the NIH Public Access Policy.

This study was supported by the funding of the Affiliated Tumor Hospital of Harbin Medical University (JJZ2010-04), the 'Wu Liande' funding of Harbin Medical University (WLD-QN1118), the National Natural Science Fund (81172498), the Special Fund of Translational Medical Research between China and Russia (CR201402) and the Heilongjiang Province Science Fund (QC2015113).

\section{COMPETING FINANCIAL INTERESTS}

The authors declare no competing financial interests.

\section{REFERENCES}

1. Elmore JG, Barton MB, Moceri VM, Polk S, Arena PJ, Fletcher SW. Ten-year risk of false positive screening mammograms and clinical breast examinations. N Engl J Med. 1998; 338:1089-1096.

2. Dulaimi E, Hillinck J, de Caceres I I, Al-Saleem T, Cairns P. Tumor suppressor gene promoter hypermethylation in serum of breast cancer patients. Clin Cancer Res. 2004; 10:6189-6193.

3. Muller HM, Widschwendter A, Fiegl H, Ivarsson L, Goebel G, Perkmann E, Marth C, Widschwendter M. DNA methylation in serum of breast cancer patients: an independent prognostic marker. Cancer Res. 2003; 63:7641-7645.

4. Baylin SB, Herman JG, Graff JR, Vertino PM, Issa JP. Alterations in DNA methylation: a fundamental aspect of neoplasia. Adv Cancer Res. 1998; 72:141-196.

5. Jones PA, Laird PW. Cancer epigenetics comes of age. Nat Genet. 1999; 21:163-167.

6. Lehmann U, Langer F, Feist H, Glockner S, Hasemeier B, Kreipe H. Quantitative assessment of promoter hypermethylation during breast cancer development. Am J Pathol. 2002; 160:605-612.

7. Holst CR, Nuovo GJ, Esteller M, Chew K, Baylin SB, Herman JG, Tlsty TD. Methylation of p16(INK4a) promoters occurs in vivo in histologically normal human mammary epithelia. Cancer Res. 2003; 63:1596-1601.
8. Sidransky D. Emerging molecular markers of cancer. Nat Rev Cancer. 2002; 2:210-219.

9. Laird PW. The power and the promise of DNA methylation markers. Nat Rev Cancer. 2003; 3:253-266.

10. Leon SA, Shapiro B, Sklaroff DM, Yaros MJ. Free DNA in the serum of cancer patients and the effect of therapy. Cancer Res. 1977; 37:646-650.

11. Esteller M, Sanchez-Cespedes M, Rosell R, Sidransky D, Baylin SB, Herman JG. Detection of aberrant promoter hypermethylation of tumor suppressor genes in serum DNA from non-small cell lung cancer patients. Cancer Res. 1999; 59:67-70.

12. Sanchez-Cespedes M, Esteller M, Wu L, Nawroz-Danish H, Yoo GH, Koch WM, Jen J, Herman JG, Sidransky D. Gene promoter hypermethylation in tumors and serum of head and neck cancer patients. Cancer Res. 2000; 60:892-895.

13. Hibi K, Robinson CR, Booker S, Wu L, Hamilton SR, Sidransky D, Jen J. Molecular detection of genetic alterations in the serum of colorectal cancer patients. Cancer Res. 1998; 58:1405-1407.

14. Hoque MO, Feng Q, Toure P, Dem A, Critchlow CW, Hawes SE, Wood T, Jeronimo C, Rosenbaum E, Stern J, Yu M, Trink B, Kiviat NB, et al. Detection of aberrant methylation of four genes in plasma DNA for the detection of breast cancer. J Clin Oncol. 2006; 24:4262-4269.

15. Brooks J, Cairns P, Zeleniuch-Jacquotte A. Promoter methylation and the detection of breast cancer. Cancer Causes Control. 2009; 20:1539-1550.

16. Kagan J, Srivastava S, Barker PE, Belinsky SA, Cairns P. Towards Clinical Application of Methylated DNA Sequences as Cancer Biomarkers: A Joint NCI's EDRN and NIST Workshop on Standards, Methods, Assays, Reagents and Tools. Cancer Res. 2007; 67:4545-4549.

17. Van De Voorde L, Speeckaert R, Van Gestel D, Bracke M, De Neve W, Delanghe J, Speeckaert M. DNA methylationbased biomarkers in serum of patients with breast cancer. Mutat Res. 2012; 751:304-325.

18. Byun HM, Siegmund KD, Pan F, Weisenberger DJ, Kanel G, Laird PW, Yang AS. Epigenetic profiling of somatic tissues from human autopsy specimens identifies tissueand individual-specific DNA methylation patterns. Hum Mol Genet. 2009; 18:4808-4817.

19. Suijkerbuijk KP, van Diest PJ, van der Wall E. Improving early breast cancer detection: focus on methylation. Ann Oncol. 2011; 22:24-29.

20. Novak P, Jensen TJ, Garbe JC, Stampfer MR, Futscher BW. Stepwise DNA methylation changes are linked to escape from defined proliferation barriers and mammary epithelial cell immortalization. Cancer Res. 2009; 69:5251-5258.

21. Xu J, Shetty PB, Feng W, Chenault C, Bast RC Jr, Issa JP, Hilsenbeck SG, Yu Y. Methylation of HIN-1, RASSF1A, RIL and CDH13 in breast cancer is associated with clinical characteristics, but only RASSF1A methylation is associated with outcome. BMC Cancer. 2012; 12:243. 
22. Esteller M. Cancer epigenomics: DNA methylomes and histone-modification maps. Nat Rev Genet. 2007; 8:286-298.

23. Wittenberger T, Sleigh S, Reisel D, Zikan M, Wahl B, Alunni-Fabbroni M, Jones A, Evans I, Koch J, Paprotka T, Lempiainen H, Rujan T, Rack B, et al. DNA methylation markers for early detection of women's cancer: promise and challenges. Epigenomics. 2014; 6:311-327.

24. Gonzalez R, Silva JM, Sanchez A, Dominguez G, Garcia JM, Chen XQ, Stroun M, Provencio M, Espana P, Anker P, Bonilla F. Microsatellite alterations and TP53 mutations in plasma DNA of small-cell lung cancer patients: follow-up study and prognostic significance. Ann Oncol. 2000; 11:1097-1104.

25. Nawroz H, Koch W, Anker P, Stroun M, Sidransky D. Microsatellite alterations in serum DNA of head and neck cancer patients. Nat Med. 1996; 2:1035-1037.

26. Goessl C, Heicappell R, Munker R, Anker P, Stroun M, Krause H, Muller M, Miller K. Microsatellite analysis of plasma DNA from patients with clear cell renal carcinoma. Cancer Res. 1998; 58:4728-4732.

27. Schwarzenbach H, Hoon DS, Pantel K. Cell-free nucleic acids as biomarkers in cancer patients. Nat Rev Cancer. 2011; 11:426-437.

28. Chiou HC, Tangco MV, Levine SM, Robertson D, Kormis $\mathrm{K}, \mathrm{Wu} \mathrm{CH}, \mathrm{Wu} \mathrm{GY}$. Enhanced resistance to nuclease degradation of nucleic acids complexed to asialoglycoprotein-polylysine carriers. Nucleic Acids Res. 1994; 22:5439-5446.

29. Christensen BC, Houseman EA, Marsit CJ, Zheng S, Wrensch MR, Wiemels JL, Nelson HH, Karagas MR, Padbury JF, Bueno R, Sugarbaker DJ, Yeh RF, Wiencke $\mathrm{JK}$, et al. Aging and environmental exposures alter tissuespecific DNA methylation dependent upon $\mathrm{CpG}$ island context. PLoS Genet. 2009; 5:e1000602.

30. Virmani AK, Tsou JA, Siegmund KD, Shen LY, Long TI, Laird PW, Gazdar AF, Laird-Offringa IA. Hierarchical clustering of lung cancer cell lines using DNA methylation markers. Cancer Epidemiol Biomarkers Prev. 2002; 11:291-297.

31. Eads CA, Danenberg KD, Kawakami K, Saltz LB, Blake C, Shibata D, Danenberg PV, Laird PW. MethyLight: a highthroughput assay to measure DNA methylation. Nucleic Acids Res. 2000; 28:E32.

32. Nothacker M, Duda V, Hahn M, Warm M, Degenhardt F, Madjar H, Weinbrenner S, Albert US. Early detection of breast cancer: benefits and risks of supplemental breast ultrasound in asymptomatic women with mammographically dense breast tissue. A systematic review. BMC Cancer. 2009; 9:335.

33. Teh W, Wilson AR. The role of ultrasound in breast cancer screening. A consensus statement by the European Group for Breast Cancer Screening. Eur J Cancer. 1998; 34:449-450.
34. Mandelson MT, Oestreicher N, Porter PL, White D, Finder CA, Taplin SH, White E. Breast density as a predictor of mammographic detection: comparison of intervaland screen-detected cancers. J Natl Cancer Inst. 2000; 92:1081-1087.

35. McCormack VA, dos SSI. Breast density and parenchymal patterns as markers of breast cancer risk: a meta-analysis. Cancer Epidemiol Biomarkers Prev. 2006; 15:1159-1169.

36. Boyd NF, Guo H, Martin LJ, Sun L, Stone J, Fishell E, Jong RA, Hislop G, Chiarelli A, Minkin S, Yaffe MJ. Mammographic density and the risk and detection of breast cancer. N Engl J Med. 2007; 356:227-236.

37. Bediaga NG, Acha-Sagredo A, Guerra I, Viguri A, Albaina C, Ruiz DI, Rezola R, Alberdi MJ, Dopazo J, Montaner D, de Renobales M, Fernandez AF, Field JK, et al. DNA methylation epigenotypes in breast cancer molecular subtypes. Breast Cancer Res. 2010; 12:R77.

38. Fackler MJ, Umbricht CB, Williams D, Argani P, Cruz LA, Merino VF, Teo WW, Zhang Z, Huang P, Visvananthan K, Marks J, Ethier S, Gray JW, et al. Genome-wide Methylation Analysis Identifies Genes Specific to Breast Cancer Hormone Receptor Status and Risk of Recurrence. Cancer Res. 2011; 71:6195-6207.

39. Holm K, Hegardt C, Staaf J, Vallon-Christersson J, Jonsson G, Olsson H, Borg A, Ringner M. Molecular subtypes of breast cancer are associated with characteristic DNA methylation patterns. Breast Cancer Res. 2010; 12:R36.

40. Bloushtain-Qimron N, Yao J, Snyder EL, Shipitsin M, Campbell LL, Mani SA, Hu M, Chen H, Ustyansky V, Antosiewicz JE, Argani P, Halushka MK, Thomson JA, et al. Cell type-specific DNA methylation patterns in the human breast. Proc Natl Acad Sci U S A. 2008; 105:14076-14081.

41. Soong R, Robbins PD, Dix BR, Grieu F, Lim B, Knowles S, Williams KE, Turbett GR, House AK, Iacopetta BJ. Concordance between $\mathrm{p} 53$ protein overexpression and gene mutation in a large series of common human carcinomas. Hum Pathol. 1996; 27:1050-1055.

42. Hugh J, Hanson J, Cheang MC, Nielsen TO, Perou CM, Dumontet C, Reed J, Krajewska M, Treilleux I, Rupin M, Magherini E, Mackey J, Martin M, et al. Breast cancer subtypes and response to docetaxel in node-positive breast cancer: use of an immunohistochemical definition in the BCIRG 001 trial. J Clin Oncol. 2009; 27:1168-1176.

43. Livak KJ, Schmittgen TD. Analysis of relative gene expression data using real-time quantitative PCR and the 2(-Delta Delta C(T)) Method. Methods. 2001; 25:402-408.

44. Cho YH, Shen J, Gammon MD, Zhang YJ, Wang Q, Gonzalez $\mathrm{K}, \mathrm{Xu} \mathrm{X}$, Bradshaw PT, Teitelbaum SL, Garbowski G, Hibshoosh H, Neugut AI, Chen J, et al. Prognostic significance of gene-specific promoter hypermethylation in breast cancer patients. Breast Cancer Res Treat. 2012; 131:197-205.

45. 45. Sergeant G, Penninckx F, Topal B. Quantitative RT-PCR detection of colorectal tumor cells in peripheral blood--a systematic review. J Surg Res. 2008; 150:144-152. 